\title{
Predicting Health Behaviors with an Experimental Measure of Risk Preference ${ }^{\dagger}$
}

\author{
Lisa R. Anderson \\ College of William and Mary \\ Jennifer M. Mellor ${ }^{\ddagger}$ \\ College of William and Mary \\ College of William and Mary \\ Department of Economics \\ Working Paper Number 59 \\ September 2007, revised April 2008
}

${ }^{\dagger}$ Financial support for this research was provided by the Schroeder Center for Healthcare Policy at the Thomas Jefferson Program in Public Policy at the College of William \& Mary and the FINRA Investor Education Foundation. We are grateful to Anderson's co-PIs Julie Agnew, Jeff Gerlach, and Lisa Szykman for agreeing to add the health behaviors component to the FINRA project. We also thank Editor Richard Frank and two anonymous referees for their helpful comments and suggestions.

${ }^{\ddagger}$ Corresponding Author: phone 757-221-2852, fax 757-221-1175 
COLLEGE OF WILLIAM AND MARY

DEPARTMENT OF ECONOMICS

WORKING PAPER \# 59

September 2007, revised April 2008

\title{
Predicting Health Behaviors with an Experimental Measure of Risk Preference
}

\begin{abstract}
We conduct a large-scale economics experiment paired with a survey to examine the association between individual risk preference and health-related behaviors among adults aged 18 to 87 years. Risk preference is measured by the Holt and Laury (2002) lottery choice experiment. Controlling for subject demographic and economic characteristics, we find that risk aversion is negatively and significantly associated with cigarette smoking, heavy drinking, being overweight or obese, and seat belt non-use. In additional specifications, we find that risk aversion is negatively and significantly associated with the likelihood a subject engaged in any of five risky behaviors and the number of risky behaviors reported.
\end{abstract}

JEL Codes: I12, C91

Keywords: risk preference, lottery choice experiment, health risk behaviors, smoking

Lisa R. Anderson

Department of Economics

College of William and Mary

Williamsburg, VA 23187-8795

lrande@wm.edu
Jennifer M. Mellor

Department of Economics

Thomas Jefferson Program in Public Policy

College of William and Mary

Williamsburg, VA 23187-8795

jmmell@wm.edu 


\section{Introduction}

Risk preference influences a variety of economic behaviors under uncertainty, such as investment, portfolio choice, job change, and migration. In the field of health economics, attitudes toward risk are likely to affect the purchase of health insurance, the use of preventive medical care, and the propensity to engage in behaviors that either increase or decrease mortality risk, such as cigarette smoking or seat belt use. Despite the importance of individual-specific risk preference, there is no consensus on how best to measure it or control for its contribution to economic behaviors. Recent studies have employed various survey questions dealing with hypothetical gambles (e.g., Barsky et al. 1997), hypothetical willingness to pay for risky assets (e.g., Guiso and Paiella 2005), and self-reported attitudes toward risk (e.g., Dohmen et al. 2005). These survey-based measures of risk preference have shown the expected relationship with risky health-related behaviors in some, but not all, such studies. One concern about survey questions is that choices made in hypothetical situations may not reflect actual behaviors when real money is at stake. Further, evidence from experimental economics suggests that respondents' reports of their own attitudes do not always reflect their actual behaviors (e.g., Glaeser et al. 2000). These issues motivate the use of economics experiments to generate additional measures of subjectspecific risk preference.

The primary contribution of this paper is a methodological one. We pair a widely-used economics experiment designed to measure risk preference (the lottery choice experiment designed by Holt and Laury 2002) with a survey that measures several risky health-related behaviors, and we use the resulting data to test whether risk preference measured by the experiment is associated with surveyed behaviors. This general approach has been reported in 
only a few prior studies, and ours is the first study to focus exclusively on health behaviors. Our methodological contribution is enhanced by the use of a subject pool that is both large and diverse when compared to those derived from most economics experiments, many of which consist of undergraduate students. Using data from one of the largest replications of the lottery choice experiment, we examine a sample of more than a thousand adult subjects ranging from 18 to 87 years of age. All subjects in our experiment received immediate financial payments based on their decisions, so that the stakes in the lotteries were not simply hypothetical.

Our empirical results show that an experimental measure of risk preference is significantly associated with several risky health behaviors measured in our survey. Controlling for a number of subject demographic and economic traits, we find that laboratory-measured risk aversion is negatively and significantly associated with cigarette smoking, heavy episodic drinking, being overweight or obese, and seat belt non-use. In other specifications, we find that the experimental measure of risk aversion is negatively and significantly associated with the likelihood of reporting any of five risky behaviors, the number of risky behaviors reported, and a factor-analysis-based measure of subjects' underlying propensity to engage in risky behavior. Thus, our findings provide additional evidence that certain health behaviors are influenced in a consistent manner by preferences toward risk. Because two of the behaviors significantly associated with our experimental measure of risk aversion are smoking and seat belt non-use, our results also offer additional support for the use of these behaviors as proxies for risk preference. Finally, our findings demonstrate the potential benefits of linking experimental tasks to household surveys. 


\section{Measuring Individual-Specific Risk Attitudes}

Before introducing our methodological approach, we first describe existing techniques for measuring individual-specific attitudes toward risk. The literature review makes several points relevant to our work. First, there is no single or standard choice of proxy for risk preference. Second, only a small number of studies have used experimental measures to generate a measure of risk preference and examine its relation to risky behaviors. Third, compared to these prior studies, our work has a unique focus on health behaviors and draws on a subject pool that is both exceptionally large and diverse in age.

Past research studies have measured individual-specific attitudes toward risk with measures of hypothetical behaviors, actual behaviors, and self-reported attitudes. Among the measures involving hypothetical scenarios, the most common deals with hypothetical gambles. For example, questions on the 1992 Health and Retirement Study (HRS) ask respondents to choose between two jobs, one with a certain income and another with a 50\% chance of doubling income and a 50\% chance of reducing income by one-third, one-fifth, or one-half. Based on their job choices, respondents can be classified into one of four categories ranging from least risk tolerant to most risk tolerant ${ }^{1}$; alternatively, it is possible to construct a cardinal measure of risk tolerance from the responses as is done in Barsky et al. (1997). Variations of these questions have also appeared in the Panel Study of Income Dynamics (PSID) (e.g., Luoh and Stafford 1997), a 1997 survey of French households (e.g., Arrondel 2002) and a 1998 survey of Dutch households (e.g., Kapteyn and Teppa 2002). In all cases, the questions offered subjects the choice of a safe job with certain earnings of $Y$ and a risky job with expected earnings greater than

\footnotetext{
${ }^{1}$ In later waves of the HRS, additional questions increase the number of categories to six.
} 
$Y$. As a result, the questions can be used to classify subjects at different levels of risk aversion, but not as risk-loving or risk neutral.

Measures derived from hypothetical gamble questions have been used to predict healthrelated risky behaviors in a number of studies. ${ }^{2}$ For example, controlling for age, sex, race, and religion, Barsky et al. (1997) reported that respondents in the HRS with larger parameter values of risk tolerance were more likely to smoke, drink, and not own health insurance. In contrast, Picone, Sloan and Taylor (2004) found that the coefficient on a risk tolerance parameter was either statistically insignificant or significant and of the wrong sign in models of the demand for preventive medical tests. Sloan and Norton (1997) reported insignificant coefficients on categorical dummies for risk aversion in a model of long-term care insurance demand. Lahiri and Song (2000) reported that a categorical dummy for risk aversion had a negative and significant effect in a model of smoking initiation but an insignificant effect in a model of smoking continuation. Finally, Dave and Saffer (2007) found that a categorical dummy for risk aversion had a negative and significant coefficient in models of alcohol consumption.

Individual risk preference has also been measured with questions on other hypothetical behaviors. For example, Guiso and Paiella (2005) used hypothetical willingness to pay for a risky asset to examine decision making in the 1995 Bank of Italy Survey of Household Income and

${ }^{2}$ Additional studies have employed the hypothetical gamble questions to control for risk preferences in models of behaviors unrelated to health. Using the HRS, these include Lusardi (1998) on precautionary saving behavior, and Kimball, Sahm and Shapiro (2007) on asset allocation. Using the PSID, Charles and Hurst (2003) examined investment decisions, Kan (2003) examined mobility, Brown and Taylor (2007) modeled educational attainment and wages, and Schmidt (2007) studied marriage and childbearing. Kapteyn and Teppa (2002) and Arrondel (2002) examined wealth and investment using Dutch and French household data, respectively. 
Wealth. ${ }^{3}$ Risk aversion indicators had significant negative effects on the likelihood of having a chronic disease, but unexpected negative effects in models of health insurance ownership. ${ }^{4}$

Another approach is to use measures of actual behaviors to proxy for risk preference. For example, Viscusi and Hersch (2001) and Hakes and Viscusi (2007) used smoking status to control for risk preference in models of job risk-taking and seat belt use, respectively. In related work, Hersch and Viscusi (1998) showed that smoking status predicted risk-reducing preventive health behaviors, such as tooth flossing and blood pressure monitoring. One concern about using smoking to capture risk preference is that it may also reflect time preference (e.g., Fuchs 1982, Evans and Montgomery 1994). However, the same concern is unlikely to apply to seat belt nonuse, another behavioral measure of risk preference. Hersch and Viscusi (1990) validated both smoking and seat belt use as proxies of risk tolerance in a study of compensating differentials for risky jobs.

Finally, questions on self-reported attitudes are another means of measuring individual risk preferences. Dohmen et al. (2005) is a notable example of this approach. ${ }^{5}$ More than 20,000 subjects from German households were surveyed about their general willingness to take risks on a scale of 0 to 10 . A binary measure of risk tolerance constructed from this scale was used in

${ }^{3}$ Hartog, Ferrer-i-Carbonell and Jonker (2000) also used this type of survey question, and Kruse and Thompson (2003) used a survey question on willingness to pay for a risk mitigation device. Neither study focused on the relationship between risk attitudes and reported health behaviors.

${ }^{4}$ These measures had significant coefficients of the expected sign in models of selfemployment, ownership of risky assets, moving, and changing jobs.

${ }^{5}$ In another such study, Kaptyn and Teppa (2002) used attitudinal measures of risk tolerance to predict portfolio choice. 
models of various behaviors, and found to have positive and significant effects on smoking participation, stock investment, self-employment, and sports participation. ${ }^{6}$

The Dohmen et al. study is especially relevant to our work because it also provides an experimental validation of the attitudinal risk tolerance measure using a representative sample of 450 adult individuals living in Germany. Subjects in this sample completed a questionnaire containing the same set of attitudinal questions used in the larger survey, and then participated in a lottery choice experiment. For each of twenty decision rows, subjects had to choose either a lottery with expected winnings of 150 Euros, or a safe monetary amount that increased in size across the rows from 0 Euros to 190 Euros. The point at which subjects switched from the lottery to the safe option indicated risk preferences: the higher the value of the safe option at the switch point, the more risk tolerant the subject. The survey-based attitudinal measure of risk tolerance was found to be a significant predictor of the experimental measure even upon controlling for a number of subject traits. Thus this study provided important validation of the attitudinal measure of risk-taking, although the authors did not report whether the experimental measure of risk-taking was itself associated with smoking status. It is also worth noting that while large monetary payoffs were used to motivate incentive-compatible decision-making, subjects were informed that only one in seven would be paid for their decisions, and payments were made in checks sent by mail.

We know of only a few other studies that use economics experiments to both measure

${ }^{6}$ Dohmen et al. (2005) also employed five measures of willingness to take risks in specific domains; three of these had positive and significant coefficients in the smoking model. Another risk preference measure was based on subject responses to a question about the fraction of hypothetical lottery winnings they would invest in a risky asset. This measure was not significantly related to smoking. 
risk preference and compare the resulting measure to survey-based questions on risky behavior. Kruse and Thompson (2003) took this approach in studying the hypothetical willingness to pay for a risk mitigation device. They compared subject responses about willingness to pay for a lock that reduced the chance of burglary to subject play in an experiment with identical losses and probabilities, but with real money at stake. The experimental and survey-based measures were consistent on average, but on an individual level they were consistent for less than one-quarter of the subjects. Lusk and Coble (2005) compared subject responses to survey questions on the willingness to consume genetically-modified foods to subject decisions in a lottery choice experiment. Their results are described in detail in the next section (since they use the same lottery choice experiment we employ), but their main finding is that the experimental measure was significantly associated with risk-taking behavior.

While our study is related to these three prior studies, it makes several new contributions. First, our study is the first to pair an experimental measure of risk preference with several common health risk behaviors. Findings from Dohmen et al. (2005) suggest that an experimental measure might be associated with smoking, but this was not explicitly examined; moreover the majority of subjects in the experiment were not paid based on their lottery choices. Second, our study uses an exceptionally large sample of more than a thousand subjects, roughly twice the number used in Dohmen et al. and twenty times the sample size used in Lusk and Coble (2005). Finally, while our data do not allow us to make direct comparisons of all measures of risk preference described above, we are able to compare our experimental measure of risk preference to two commonly-used measures defined from actual behaviors, seat belt non-use and smoking. In this way, our results are able to inform the choice of proxy measures used in future studies. 


\section{An Experimental Measure of Risk Preference}

To examine whether an experimental measure of risk preference is associated with health-related behaviors, we used data from a large-scale experiment involving more than one thousand subjects. We employed one of the most widely-used experiments designed to capture risk preference - the lottery choice task from Holt and Laury (2002). A major advantage of this design relative to other experiment-based studies of risk aversion is that the task is simple and context free. Another advantage is that subjects are not placed in the role of buyer and seller to elicit certainty equivalents, which is important given ample evidence that the amount subjects are willing to accept for an item is often significantly higher than the amount they are willing to pay, especially for goods without close substitutes such as reduced health risks (Horowitz and McConnell 2002). Additionally, this experimental measure can be used to identify subjects with risk-loving or risk neutral preferences, unlike some alternate measures.

A major advantage of using an experiment to measure risk preference is that it can provide incentive-compatible measures of subject traits; in our case this comes from paying all subjects in cash at the end of the experiment based on their lottery choices. However, it should be noted that there is not unanimous support for linking measures of financial risk tolerance to measures of risk tolerance in other settings, such as health, employment, or mobility. In fact, Kaplow (2005) found that estimates of individual risk aversion from the financial economics literature did not reconcile with estimates of the value of a statistical life from the labor economics literature. Psychological evidence also suggests that risk tolerance is a domainspecific trait, likely because of differences in the way individuals perceive the riskiness of specific activities (Weber, Blais, and Betz 2002), but this issue is still debated. For example, 
Dohmen et al. (2005) reported that the correlation coefficients for measures of general attitudes toward risk and several context-specific attitudes toward risk were large and highly significant. While fully resolving whether risk tolerance is domain-specific or generalized is beyond the scope of this paper, our work follows many of the studies cited earlier in attempting to link a financial-based measure to non-financial behavior.

In the basic Holt and Laury design, subjects made 10 choices between Lottery A and Lottery B. Lottery A paid either $\$ 2.00$ or $\$ 1.60$ and Lottery B paid either $\$ 3.85$ or $\$ 0.10$. In any decision row, Lottery A was the "safe" choice, and Lottery B was "risky" since Lottery A had less variability in the payoffs than Lottery B. The decision rows differed in terms of the probability of winning the higher prize in each lottery. In Decision 1, the higher prize (either $\$ 2.00$ or $\$ 3.85$ ) was paid if the throw of a 10 -sided die was 1 and the lower prize (either $\$ 1.60$ or $\$ 0.10$ ) was paid for any other throw of the die. For Decision 2, the higher prize was paid if the result of the die throw was 1 or 2 and the lower prize was paid if the die throw was 3 through 9 . This pattern continued so that by Decision 9 there was a $90 \%$ chance of winning the higher prize, and that Decision 10 was a choice between a certain $\$ 2.00$ for Lottery A and a certain $\$ 3.85$ for Lottery B. Once all 10 decisions were made, a die toss determined which decision row (1 through 10) would be chosen for payment, and a second die toss determined the result of the particular lottery chosen by the subject. ${ }^{7}$

Table 1 shows the paired lottery choices for the 10 decisions in our experimental design,

${ }^{7}$ Note that subjects in the experiment were not faced with the possibility of a financial loss of their own money; few experimental designs incorporate such a feature out of concerns related to human subjects approval and recruitment. Nonetheless, Clark (2002) compared subject behavior in a public goods game with own-money and "house-money" treatments and found no difference in average contributions. 
in which payoffs are three times the Holt and Laury (2002) baseline amounts. ${ }^{8}$ In Decisions 1 through 4, the expected payoff for Lottery A is higher than the expected payoff for Lottery B; in Decisions 5 though 10, Lottery B has a higher expected payoff. Thus, Lottery A, the safe choice, will be chosen four times by a risk neutral subject, more than four times by a risk averse subject, and less than four times for a risk-loving subject. In Holt and Laury (2002), the lottery choice experiment was conducted with 212 subjects who were a mix of undergraduate students, MBA students, and business school faculty. Twenty-six percent of the subjects were risk neutral, $8 \%$ were risk loving, and $66 \%$ were risk averse.

The Holt and Laury (2002) design has been used in many subsequent studies to examine risk attitudes. For example, Harrison, Lau, and Rutstrom (2007) studied the relationship between demographic characteristics and lottery choice decisions using a Dutch subject pool, and Harrison, List and Towe (2007) ran the lottery choice experiment in the context of a rare coin market to examine the effects of framing and background risk. Two studies used the Holt and Laury (2002) lottery choice experiment to study risk preferences of workers who chose occupations with risky income streams. ${ }^{9}$

${ }^{8}$ Though tripled, our payoffs still result in an average payment of $\$ 7$, which may be low relative to the value of subjects' time. This may result in lower levels of measured risk aversion, based on findings from Holt and Laury (2002). They directly tested the effect of payoff amounts on subject behavior by having subjects repeat the series of 10 decisions under four payoff treatments. The low payoff treatment is described above and the high payoff treatments scaled up the low payoffs by a factor of either 20,50 , or 90 . While the scale of payoffs did not affect behavior when payoffs were hypothetical, increasing the scale of real payoffs made subjects act more risk averse on average.

${ }^{9}$ Bellemare and Shearer (2006) conducted the experiment using Canadian tree planters as subjects and reported that their subjects were generally more risk tolerant than the Holt and Laury subjects. Similarly, Elston, Harrison, and Rutström (2005) conducted the experiment at two small business conventions and reported that full-time entrepreneurs were significantly more risk 
As noted earlier, our study is closely related to Lusk and Coble (2005) which used the Holt and Laury (2002) lottery choice experiment to predict preferences for and consumption of genetically modified food. Subjects made a series of ten choices with real payoffs roughly five times the amounts used in the Holt and Laury (2002) low payoff treatment. ${ }^{10}$ Fifty undergraduate students participated, and average earnings were $\$ 12$ (plus a \$10 show up payment). Lusk and Coble (2005) found that individuals who were more risk averse in the lottery choice experiment were significantly less likely to report purchasing and eating genetically-modified food on a postexperiment survey. Like Lusk and Coble (2005) we focus on the relationship between a measure of risk preference defined from the lottery choice experiment and measures of risky behaviors. Our focus is on behaviors that have well-known and significant risks to health status, such as smoking, alcohol use, and seat belt non-use. We know of no previous study that pairs a lottery choice experiment with survey-based measures of these health-related decisions. Finally we use a considerably larger subject pool, which we describe in the next section.

\section{Experimental Methods}

Non-student adult subjects were recruited from the greater Williamsburg, Virginia area by contacting a variety of local organizations and posting flyers in public places. Student subjects were recruited from various undergraduate and graduate courses at the College of William and Mary. A total of 1,094 subjects participated in the experiment, making this study one of the

tolerant than part-time entrepreneurs and non-entrepreneurs.

${ }^{10}$ Lottery A, the safe choice, earned subjects either $\$ 10$ or $\$ 8$ and Lottery $B$, the risky choice, earned subjects either $\$ 19$ or $\$ 1.00$. 
largest replications of the lottery choice experiment. Prior to the experiment, instructions were distributed to subjects and read aloud. Subjects then made 10 decisions with real payoffs that were three times the low payoffs used in Holt and Laury (2002). Appendix 1 includes copies of the instructions and decision sheet. Once all decisions were recorded, one of the ten was randomly chosen for payment, and earnings averaged $\$ 6.90 .{ }^{11}$

In our lottery choice experiment and in others, subjects generally begin by choosing Option A (the safe option) in Decision 1, when the chance of winning the higher Option B payoff is relatively small. The point at which subjects switch from the safe option to the risky option can be used to define a range of values for the subject's risk aversion parameter. We follow Holt and Laury's procedures for defining upper and lower bounds on this parameter by assuming a utility function of constant relative risk aversion:

(1) $U(Y)=\frac{Y^{1-\gamma}}{1-r}$

where $r$ is the coefficient of relative risk aversion (CRRA), and $Y$ is the payoff in the lottery. To illustrate, consider an individual who chooses the safe option in the first three decisions, then chooses the risky option for each subsequent decision. The lower bound of the CRRA can be determined by solving for $r$ such that the individual is indifferent between Option A and Option B at Decision 3:

${ }^{11}$ Once all subjects completed and were paid for the lottery choice experiment they took part in a financial investment experiment that is the subject of a separate manuscript (Agnew et al. 2008). 
(2) $0.3 \frac{6}{1-r}^{1-r}+0.7 \frac{4.80^{1-r}}{1-r}=0.3 \frac{11.55^{1-r}}{1-r}+0.7 \frac{0.30^{1-\gamma}}{1-r} \Leftrightarrow r \equiv-0.49$

For the same individual, the upper bound is $r$ such that the individual is indifferent between Option A and Option B at Decision 4:

(3) $0.4 \frac{6}{1-r}^{1-r}+0.6 \frac{4.80^{1-r}}{1-r}=0.4 \frac{11.55^{1-r}}{1-r}+0.6 \frac{0.30^{1-r}}{1-r} \Leftrightarrow r \equiv-0.15$

Values of $r<0$ indicate risk-loving preferences, $r=0$ indicates risk neutrality, and values of $r>0$ indicate risk aversion. For subjects who switch from Option A to Option B a single time, these ranges are reported in Table 2. We discuss other cases in more detail below.

At the end of the experiment, subjects completed a survey that began with questions about demographic traits including age, sex, race, educational attainment, household income and household size. ${ }^{12}$ The survey included seven health-related questions: one each on cigarette smoking, height and weight (used to define body mass index), seat belt use, driving over the speed limit, and two questions on alcohol consumption. These questions are reprinted in Appendix 2. With one exception (driving over the speed limit), they were adapted from the CDC's Behavioral Risk Factor Surveillance System.

The behaviors measured in our survey represent some of the most significant and wellknown behavioral influences on health status. Tobacco use, alcohol consumption, and behaviors tied to overweight and obesity are thought to explain almost 40 percent of U.S. deaths annually

12 The majority of survey questions dealt with subject experiences and attitudes about the financial investment experiment described in Agnew et al. (2008). 
(e.g., Mokdad et al. 2004). Seat belt use has long been studied in the context of behavioral risks

(e.g., Peltzman 1975, and more recently Hakes and Viscusi 2007) and is significantly associated with reductions in traffic fatalities (Department of Transportation 1984). The evidence linking injuries with driving over posted speed limits is less clear cut, but some studies suggest that speeding is a contributing factor in nearly 30 percent of all fatal crashes (NHTSA 1997). In the next section, we report results from the lottery choice experiment and from models of these behaviors that include the experimental measure of risk preference as an explanatory variable.

\section{Estimation and Results}

Of the 1,094 subjects who participated in the experiment, we excluded three subjects who left at least one of the ten lottery choice decisions blank. Table 2 shows the distribution of the number of safe choices made by the remaining 1,091 subjects, which appears very similar to that reported in other lottery choice experiments. Like those of other studies, our results also suggest a considerable amount of heterogeneity in risk preferences. The majority of subjects made either four (23\%), five (26\%) or six (20\%) safe decisions. The comparable percentages reported in Holt and Laury (2002) are 26\%, 26\%, and 23\%, and 24\%, $12 \%$ and $24 \%$ in Lusk and Coble (2005). Fourteen percent of our subjects made three or fewer safe decisions; Holt and Laury (2002) and Lusk and Coble (2005) reported $8 \%$ and $12 \%$, respectively, in this range.

The majority of our subjects (79\%) started with Option A then switched from Option A to Option B once and played Option B thereafter. However, 21\% "switched back" to the safe option after having chosen the risky option. This type of behavior is also reported in other lottery choice experiments. In Holt and Laury (2002), 13\% of 212 subjects switched back to the safe 
option in an initial low-payoff treatment, and 7\% switched back in a second low-payoff treatment. In Lusk and Coble (2005), 6\% of 50 subjects did so. The difference in the percentage of such respondents may be attributable to the large fraction of non-students and older individuals in our subject pool. ${ }^{13}$ Like Holt and Laury (2002), we found that a large proportion (48\%) of the subjects who switched back did so only once. The comparable percentage in their sample is higher, at around $75 \%$.

For subjects who made multiple switches, we follow Harrison, List, and Towe (2007) and Lusk and Coble (2005) in determining the range of values for relative risk aversion. The lower bound of the range is determined by the first switch a subject made from the safe lottery to the risky lottery. For example, if a subject chose Lottery A for the first four decisions then switched to Lottery B for the fifth decision, we use the lower bound associated with four safe choices, which is -0.15 (from Table 2). The upper bound is determined by the last safe choice a subject makes. Continuing with the example above, if this subject switched back to Lottery A for the sixth decision and then chose Lottery B for all remaining decisions, we use the upper bound of the range of relative risk aversion associated with six safe choices, which is 0.68 (from Table 2). As Harrison, List and Towe (2007) explain, this treats subjects as if they were indifferent between the options in the intermediate decisions and have "fat preferences."

${ }^{13}$ We found evidence consistent with this when we estimated a probit model in which the dependent variable equaled 1 if the subject switched back from risky to safe, and 0 otherwise. Age had a positive and significant coefficient and an indicator for current student had a significant negative coefficient. Also of interest is that indicators for the highest income and educational categories had negative and significant coefficients. 
Forty-six subjects in our sample chose the safe option for Decision $10 .^{14}$ Because a safe choice for the tenth decision means favoring a certain $\$ 6$ over a certain $\$ 11.55$, we interpret this as a sign the subject did not understand the instructions. These subjects are excluded from our subsequent analysis. This is similar to procedures described in Harrison, List and Towe (2007), which dropped 14 of 85 subjects who showed signs of confusion or lack of motivation.

Table 3 reports descriptive statistics for the explanatory variables defined from our survey questions. We exclude the three subjects who did not make all ten pairwise lottery choice questions and the 46 subjects who chose the safe lottery in decision 10. This leaves us with 1,045 observations; missing data on the other explanatory variables in our models reduces our sample to a maximum of 978 observations, and missing data on the dependent variables (reported in Table 4) results in slightly smaller samples in our model estimations.

Our sample includes an almost even mix of males (48\%) and females (52\%). Subject age ranges from 18 to 87 years, and the average subject is 45 years old. About $13 \%$ of subjects are nonwhite; of these, the majority are African American. Our subject pool is highly educated. About one-fourth of the sample are current full-time students, another $30 \%$ hold graduate degrees and $26 \%$ have a college degree. Those whose highest level of education is high school or less comprise just over $5 \%$ of the sample. The household income question was structured with categorical responses. About $10 \%$ of the sample did not provide an income range for this question so we construct a "missing" dummy variable so as not to lose these observations. All other income dummies are coded to 0 for these individuals. Household income is skewed toward

14 This number includes the $1.5 \%$ shown in Table 2 who made exactly 10 safe decisions, and other subjects who made risky decisions in prior rows but choose safe in Decision 10. 
the upper-end of the distribution, with 31\% reporting annual household income greater than $\$ 100,000$, and another $28 \%$ reporting income between $\$ 60,000$ and $\$ 100,000$. Those with the lowest income range, less than $\$ 20,000$, represent just under $8 \%$ of the sample.

Table 4 reports the definitions and means of five variables capturing health-related behavioral risks for the sample of observations with non-missing data on the explanatory variables. About $8 \%$ of respondents reported that they smoked cigarettes every day or some days, and 7\% had an episode of heavy drinking in the past week. ${ }^{15}$ Just under half of the sample was classified as overweight or obese, based on having a body mass index (BMI) greater than $25 .{ }^{16}$ About $10 \%$ of our sample reported they did not wear seat belts "always or almost always," and $9 \%$ frequently drove over speed limits. Table 4 also reports pairwise correlation coefficients for these five variables: six of the 10 raw correlations are positive and three are statistically significant. ${ }^{17}$ Later in this section, we describe the results of a factor analysis of these outcome measures.

Compared to national averages, these risky behaviors are less common in our sample. Estimates from 2006 show that about $20 \%$ of U.S. adults were current smokers, $15 \%$ reported an episode of heavy drinking in the past month, and $62 \%$ were classified as overweight or obese (CDC 2006). NHTSA (2006) reported nationwide seat belt non-use at 19\%. There are several

${ }^{15}$ For men we defined heavy episodic drinking as having an average of five drinks or more on the days they drank; for women we used four drinks or more. These cutoffs are reported by the Journal of Studies in Alcohol.

${ }^{16}$ The body mass index is calculated as weight in pounds multiplied by 703 , then divided by height in inches squared.

${ }^{17}$ Because the five variables were binary we estimated pairwise tetrachoric correlation coefficients. 
possible explanations for these differences. In the case of drinking, differences may be attributable to slight variations in the question wording (e.g., our question referenced the past week instead of the past month). Another is that our sample consists of a high proportion of highly educated individuals. However, educational differences do not account for this entirely, since even in our college-educated subsample we observe lower rates of smoking, drinking, and overweight/obesity compared to national estimates for this group (CDC 2006). Another possibility is that the individuals who chose to participate in the experiment were different in some unobservable trait that is negatively correlated with these behaviors.

It is also possible that individuals underreported their behaviors on the survey. While we tried to minimize underreporting by using self-administered paper questionnaires that were not identified with personal data such as names or addresses, it is possible that subject responses were affected by social desirability bias. The fact that many responses were broadly defined may have limited the extent of this type of bias, although the downside to that is that we are unable to distinguish degrees of riskiness (such as those who drive 20 miles per hour above the speed limit versus those who drive $5 \mathrm{MPH}$ over the limit). Although it is not possible to quantify the relative contributions of these factors or the degree of underreporting, measurement error in binary dependent variables is known to produce attenuated coefficient estimates (Hausman 2001). In this case, our results would underestimate the true relationship between CRRA and behavioral health risks.

We next examine the association between these behavioral health risks and a measure of risk preference defined from our lottery choice experiment. We estimate separate probit models in which a binary indicator of each risky behavior is the dependent variable, and the main 
explanatory variable is the midpoint of the subject's range of CRRA values (indicated in Table 2 for subjects with a single switchpoint from Lottery A to B, and described earlier in this section for subjects with multiple switch points). This follows Lusk and Coble (2005). All models also include controls for sex, race, age, education, income, religious affiliation, and time preference, as defined in Table $3 .{ }^{18}$ As noted earlier, lower rates of time preference may increase risky behaviors (e.g., Picone, Sloan and Taylor 2004; Khwaja, Silverman, and Sloan 2007). Religious commitment has been inversely associated with binge drinking (e.g., van Ours 2004), and studies such as Barsky et al. (1997) include religious affiliation as a control in models of risky behavior. The results from these probit models are reported as marginal effects and shown in Table 5.

The estimated marginal effect of the CRRA is negative and significant at the 5\% level in the model of overweight/obesity, negative and significant at the $10 \%$ level in models of cigarette smoking, heavy drinking, and seat belt non-use, and negative but insignificant in the model of driving over the speed limit. These results suggest that individuals who are more risk averse, as defined by having a larger CRRA from the lottery choice experiment, are significantly less likely to engage in four of five of these health risk behaviors, even upon controlling for a large number of individual traits. To evaluate the size of the marginal effect for CRRA, we consider the effect of a one standard deviation increase, or an increase of 0.41 units. This is roughly equivalent to a change from risk neutral to moderately risk averse. Using the marginal effects and dependent variable means reported in Table 5, we find that such an increase in risk aversion is associated with a 0.012 percentage point decline in the mean probability of smoking, or a $15.2 \%$ decline. The same increase in risk aversion is associated with an $8.9 \%$ decline in overweight/obesity, a

${ }^{18}$ The question on time preference in our survey is similar to one included on the HRS. 
$14.6 \%$ decline in seat belt non-use, and a statistically insignificant decline in speeding of $11.6 \%$. The decline in heavy drinking associated with this change, though statistically significant, is infinitesimal (at $0.06 \%$ ). Thus, in several cases the magnitude of the risk aversion effect is meaningfully large, albeit usually smaller than the marginal effect associated with being female or having a higher household income. We return to the relative contribution of the CRRA variable in the discussion section.

The marginal effects of demographic controls are usually significant, and many have the expected sign. The marginal effect of the female indicator is negative in all models and significant in four of the five models (the exception is in the smoking equation). This is consistent with prior evidence that binge drinking and overweight/obesity are more prevalent among men, and that women are more likely to wear seatbelts (e.g., CDC 2006; Hakes and Viscusi 2007). Age has a negative and significant effect in models of smoking, heavy drinking and speeding, and a positive and significant effect on the probability of being overweight or obese. Education and income have mixed effects. Indicators for higher educational attainment have negative and significant marginal effects in the model of cigarette smoking, but positive and significant marginal effects in the model of heavy episodic drinking. The indicators for household income are usually negative but significant only in some models and for some ranges. Religious affiliation has negative and significant effects in the models of smoking and heavy drinking.

We next examine the association between the CRRA and three summary measures of risky behavior. The first is an indicator variable equal to one if the respondent engaged in any of the five behaviors, and 0 otherwise; the second is the number of five possible risky health 
behaviors. For the third measure, we use factor analysis to form a variable that can be interpreted as the underlying propensity to engage in these five behaviors. Specifically, we use the principalfactor method to identify a construct that explains a significant amount of variance in the five outcome measures. Because all five are binary, we use a tetrachoric correlation matrix to select factors. ${ }^{19}$ We extract the first principal factor and use predicted values of this as a dependent variable. The first principal factor was the only factor to have an eigenvalue greater than 1 (a commonly-used criterion for determining the number of factors to extract), and four of the five variables loaded positively onto the first factor. Because the second principal factor had an eigenvalue of less than 0.3 , and because only three variables had positive loadings on this second factor, we did not use it in our analysis.

The results of all three models are shown in Table 6. The top panel reports models in which all five behaviors were used in the construction of the dependent variables. The first column reports the marginal effect of CRRA in the probit of any risk, the second column reports the CRRA coefficient from an ordered probit of the number of risks, and the third column reports the CRRA coefficient from an OLS regression of the first principal factor. All models also include the full set of explanatory variables shown in Table 5. In all three models, the coefficient or marginal effect of the CRRA variable has the expected negative effect. The effect is statistically significant at the 0.01 level in the first two models and significant at the 0.05 level in the third model. These results suggest that subjects who are more risk averse and have higher CRRA values are less likely to engage in any risky behavior, engage in fewer risky behaviors,

${ }^{19}$ For this exercise, we estimate the matrix using casewise deletion so the correlation coefficients presented in Table 3 differ slightly. 
and have lower estimated levels of the principal factor common to these five behaviors. These results offer additional support for the use of the experimental measure of risk preference in models of risky health behaviors.

We repeat the same exercise excluding overweight/obesity from the summary measures. We do this because of the large number of non-responses to the weight question, the concern that this measure's higher mean may be driving the results, and because the overweight indicator loaded negatively onto the first principal factor. These results are presented in the bottom panel of Table 6, and are similar in terms of the sign and statistical significance of the CRRA's marginal effect or coefficient.

We next examine the sensitivity of our results to changes in the explanatory variables included in the model, changes in the dependent variable construction, and changes in the sample. In some cases our results were robust to these changes. For example, when we reestimated models by dropping the controls for religious affiliation and financial planning time horizons, we obtained statistically significant results for the CRRA variable in all of models shown in Table 5 and 6 except two - the speeding model, where the effect of the CRRA was not significant in the first place, and the heavy drinking model, where the marginal effect lost its significance. Because religious affiliation had a significant effect in that model, we view the Table 5 model as the preferred specification. When we re-estimated models adding controls for marital status, we obtained results for the CRRA the same as those shown in Tables 5 and 6 in terms of sign and significance, with one exception - the statistical significance of CRRA in the smoking model rose to the 0.05 level.

Our results are also largely robust to changes in the sample that exclude some subjects 
who switched back and forth from the risky option to the safe option multiple times. As noted above, about one-fifth of our subjects switched back to the safe choice of Lottery A after having made the initial switch to Lottery B in an earlier row. This type of subject behavior is common in variations of the lottery choice experiment, and we followed the previous literature in dealing with these subjects. That said, the percentage of subjects who switched-back is somewhat higher in our study, and of this group, a higher percentage switched-back more than once. This raises questions about how well these subjects comprehended the task and how seriously they took it. To examine the influence of these subjects on our results, we re-estimated our models by excluding first, the roughly $4 \%$ of the sample who switched-back more than twice, and then the roughly $10 \%$ who switched back more than once. For all models using summary measures as dependent variables, the results using these two alternate samples were qualitatively similar to those shown in Table 6 in terms of the sign and significance of the CRRA effect. For the individual behavior models, excluding subjects who switched back more than once led to a loss of statistical significance for the CRRA only in the model of seat belt non-use; the statistical significance of CRRA was intact in the models of smoking, drinking and overweight/obese. The CRRA coefficient was negatively and significant in the models of smoking, drinking, overweight/obese, and seat belt non-use when subjects who switched back more than twice were excluded.

However, our results were sensitive to the definition of the dependent variables shown in Table 5. For example, when the dependent variable was defined as 1 if the individual was obese and 0 otherwise, the marginal effect of the CRRA was not significant. The same was true when heavy drinking was defined as equal to one if the respondent had at least one drink of alcohol 
every day during the past week. In the latter case, it may be that a daily glass of wine is viewed by some as a preventive measure as opposed to a risky health behavior. Changes in the construction of the other dependent variables saw similar results. When cigarette smoking was defined as smoking every day (as opposed to every day or most days), and seat belt non-use was defined as not wearing one's seat belt all of the time (as opposed to not wearing it all or most of the time), the CRRA lost statistical significance. Note that these alternate definitions of the dependent variables lowered their means, to $3.5 \%, 3.2 \%$ and $11.5 \%$ for smoking, seat belt nonuse and obesity, respectively. We chose to present the results using the original dependent variable construction in part because the means of these alternate variables are even lower than means of the original variables, and in part because the original definitions are closer to the definitions used in other studies (e.g., Hakes and Viscusi 2007, CDC 2006). While our Table 5 results show that the experimental measures can be used to predict risky behaviors, it is clear that these results are sensitive to how the behavior is defined.

\section{Discussion and Conclusions}

Survey questions on respondents' actual behaviors, hypothetical behaviors, and attitudes have been used in many empirical studies of health-related behaviors to control for individual risk preference. As Dave and Saffer (2007) explain, incorporating risk preference measures into models of risky behaviors may improve the estimation process and help to identify differential effects of economic measures or policy instruments within populations. In some studies, risk preference defined by hypothetical gamble questions had significant coefficients of the expected sign in models of health-related risks (e.g., Barsky et al. 1997), but other studies have found such 
risk preference measures to yield unexpected results (e.g., Picone, Sloan, and Taylor 2004). In response to concerns that survey questions on attitudes and hypothetical actions may lead to biased or noisy measures of preferences, a few researchers have used economics experiments to capture preferences for risk-taking, trust, and other-regarding behavior (e.g., Glaeser et al. 2000; Anderson, Mellor, and Milyo 2004). Because subjects are paid based on the decisions they make, experiments provide incentive-compatible measures.

In this paper, we examine how well an experiment-based measure of risk preference predicts several health-related behaviors. We find that risk aversion as measured by subject choices in the Holt and Laury (2002) lottery choice experiment is negatively and significantly associated with cigarette smoking, heavy drinking, being overweight or obese, and seat belt nonuse, and with several summary measures of risky behavior. These results suggest that risktaking is consistent across these multiple behaviors, both when small monetary amounts are at stake, and when the stakes include consequences for one's health. These findings can be interpreted as additional evidence that risky health behaviors are influenced in a consistent manner by this preference trait. In this regard, our findings build on earlier research by Viscusi and Hersch (2001), Hersch and Viscusi (1998) and Hakes and Viscusi (2007).

Our results offer some guidance in the choice of proxy measures employed in prior studies. While a complete assessment of the relative merits of all risk preference proxies is not possible with our data, our work does show that two actual behaviors commonly used as risk preference proxies are significantly related to our experimental measure of risk preference. That is, we find that individuals with higher levels of risk aversion in the experiment were less likely to smoke cigarettes and less likely to forego the use of a seat belt. As such our findings validate 
the use of these measures in future research.

In addition, our results have implications for both experimental economics and research based on household surveys. Our work adds to a growing number of studies on the external validity of laboratory experiments. One approach to validation is to examine whether field experiments can replicate results within a naturally-occurring environment (e.g., List 2006). For example, Harrison, List and Towe (2007) conducted a lottery choice experiment using coin dealers as subjects and rare coins as prizes, and found that field results validated lab results when there was minimal uncertainty about the value of the prize. Broadly speaking, field experiments often but do not always validate findings from laboratory experiments. Our study takes another approach to the external validation of laboratory experiments by pairing an experimental measure of risk preference with "real-world" behaviors. Building on evidence provided by Lusk and Coble (2005), which showed that lottery choice-based risk preference predicted demand for genetically-modified food, we find that the same experimental measure predicts several risky health behaviors. Our survey does not allow us to examine the association between experimental measures and preventive health behaviors (such as flu shots and cancer screening activities), and it would be interesting to examine these behaviors in future research.

Our results also contribute to an emerging discussion on the merits of pairing large household surveys with experimental economic pilots that elicit incentive-compatible measures of attitudes. The Dohmen et al. (2005) study described earlier is one such example; another is Hammoudi and Thomas (2006), which recruited several hundred rural respondents to the 2002 Mexican Family Life Survey to participate in a series of economics experiments measuring preferences. They reported that experimental measures of risk preferences and intertemporal 
choice were sometimes correlated with behaviors in ways predicted by theory. Their work is part of a larger project on the merits of integrating experiments into existing household surveys funded by the National Institutes of Health. Related projects have been funded by the National Science Foundation and private foundations.

The results presented here suggest that there are benefits to incorporating experiments into surveys. One estimate of the benefits can be derived by comparing the value of the adjusted $\mathrm{R}^{2}$ statistics from linear probability models without and with the CRRA variable. In linear probability models comparable to those in Table 5, we observe small increases in the predictive power of our models. The increase is smallest in the drinking model, from 0.1358 to 0.1364 , or just $0.4 \%$ of the baseline, and largest in the smoking model, from 0.0623 to 0.0660 , or $4.4 \%$ of baseline. When we estimate an OLS model of the number of risks, the increase in the adjusted $\mathrm{R}^{2}$ is larger, from 0.0991 to 0.1122 , or $13.2 \%$. Thus, the inclusion of the experimental measure of risk preference increases the predictive power of our models, albeit only slightly.

Of course this gain in predictive power is not costless. Across all of our sessions, subjects received average earnings of $\$ 7$ in the lottery choice experiment, making the total earnings paid just over $\$ 7,500$. For surveys in which an interviewer assists in the completion of the survey in the presence of the respondent, adding the lottery choice experiment would involve a small increase in survey time, which we estimate to be approximately 15 minutes per subject. Clearly many issues remain regarding the costs of adding experiments to national surveys that are conducted by mail or phone, the challenges more representative samples may face in completing such a task, and the merits of the experimental measure relative to its alternatives. For example, when we added an indicator variable for smoking to linear probability models of seat belt non- 
use and heavy drinking, we observed increases in adjusted $\mathrm{R}^{2}$ of $19 \%$ and $26 \%$ respectively, much larger than the increased explanatory power brought on by controlling for CRRA. Interestingly, adding seat belt non-use or smoking sometimes decreased the adjusted $\mathrm{R}^{2}$ (for example, when seat belt non-use was added to the heavy drinking model), a pattern not observed when the experimental measure was added. Thus, our findings suggest that there may be additional benefits from using an experimental measure of risk preference to predict certain health-related behaviors. 


\section{References}

Agnew, Julie, Lisa R. Anderson, Jeffrey Gerlach and Lisa Szykman. 2008. "Who Chooses Annuities? An Experimental Investigation of the Role of Gender, Defaults and Framing." Forthcoming in American Economic Review Papers and Proceedings.

Anderson, Lisa R., Jennifer M. Mellor and Jeff Milyo. 2004. "Social Capital and Contributions in a Public Goods Experiment." American Economic Review Papers and Proceedings, 94 (2): 373-376.

Arrondel, Luc. 2002. "Risk Management and Wealth Accumulation Behavior in France." Economics Letters, 74: 187-194.

Barsky, Robert B, Miles Kimball, F. Thomas Juster and Matthew Shapiro. 1997. "Preference Parameters and Behavioral Heterogeneity: An Experimental Approach in the Health and Retirement Study." Quarterly Journal of Economics, 112 (2): 537-79.

Bellemare, Charles and Bruce S. Shearer. 2006. "Sorting, Incentives and Risk Preferences: Evidence from a Field Experiment.” IZA Discussion Paper Number 2227.

Brown, Sarah, and Karl Taylor. 2007. "Education, Risk Preference, and Wages." Manuscript, Department of Economics, University of Sheffield.

Centers for Disease Control and Prevention (CDC). 2002. "Cigarette Smoking Among Adults, United States 2000.” Mortality and Morbidity Weekly Report, 51 (29): 642-645.

Centers for Disease Control and Prevention (CDC). 2006. Behavioral Risk Factor Surveillance System Survey Data. Atlanta, Georgia: U.S. Department of Health and Human Services, Centers for Disease Control and Prevention.

Charles, Kerwin Kofi, and Charles Hurst. 2003. "The Correlation of Wealth Across Generations.” Journal of Political Economy, 111: 1155-1182.

Clark, Jeremy. 2002. "House Money Effects in Public Goods Experiments.” Experimental Economics, 5: 223-231.

Dave, Dhaval and Henry Saffer. 2007. "Risk Tolerance and Alcohol Demand Among Adults and Older Adults." National Bureau of Economic Research Working Paper Number 13482.

Department of Transportation. 1984. "Regulatory Impact Analysis of FMVSS 208: Occupant Crash Protection." Washington, DC. 
Dohmen, Thomas, Armin Falk, David Huffman, Uwe Sunde, Jurgen Schupp and Gert G. Wagner. 2005. "Individual Risk Attitudes: New Evidence from a Large, Representative, Experimentally-Validated Survey.” IZA Discussion Paper Number 1730.

Elston, Julie Ann, Glenn W. Harrison and E. Elisabet Rutström. 2005. "Characterizing the Entrepreneur Using Field Experiments.” Working Paper, Max Planck Institute of Economics.

Evans, William N., and Ed Montgomery. 1994. "Education and Health: Where's There's Smoke There's An Instrument.” National Bureau of Economic Research, Working Paper 4949.

Fuchs, Victor R. 1982. "Time Preferences and Health: An Exploratory Study," in Economic Aspects of Health, edited by V.R. Fuchs, Chicago: University of Chicago Press.

Glaeser, Edward L., David I. Laibson, José A. Scheinkman and Christine L. Soutter. 2000. "Measuring Trust." Quarterly Journal of Economics, 115(3): 811-846.

Guiso, Luigi and Monica Paiella. 2005. "The Role of Risk Aversion in Predicting Individual Behavior.” Bank of Italy, Working Paper Number 546 (February).

Hakes, Jahn K., and W. Kip Viscusi. 2007. "Automobile Seatbelt Usage and the Value of a Statistical Life.” Southern Economic Journal, 73: 659-676.

Hammoudi, Amar, and Duncan Thomas. 2006. "Do You Care? Altruism and Inter-Generational Exchanges in Mexico." California Center for Population Research, University of California Los Angeles. Working Paper Number 008-06.

Hartog, Joop, Ada Ferrer-i-Carbonell and Nicole Jonker. 2000. "On a Simple Measure of Individual Risk Aversion.” Tinbergen Institute Discussion Paper TI2000-074/3.

Harrison, Glenn W., Morten Lau and Elisabet Rutström. 2007. "Estimating Risk Attitudes in Denmark: A Field Experiment." Scandinavian Journal of Economics, 109(2), June 2007, 341-368.

Harrison, Glenn W., John A List, Charles Towe. 2007. "Naturally Occurring Preferences and Exogenous Laboratory Experiments: A Case Study of Risk Aversion." Econometrica, 75 (2), 433-458.

Hausman, Jerry. 2001. "Mismeasured Variables in Econometric Analysis: Problems from the Right and Problems from the Left." Journal of Economic Perspectives, 15 (4): 57-67.

Hersch, Joni, and W. Kip Viscusi. 1990. "Cigarette Smoking, Seatbelt Use, and Differences in Wage-Risk Tradeoffs. Journal of Human Resources, 25 (2): 202-227. 
Hersch, Joni, and W. Kip Viscusi. 1998. "Smoking and Other Risky Behaviors." Journal of Drug Issues, 28 (3): 645-661.

Holt, Charles A. and Susan K. Laury. 2002. "Risk Aversion and Incentive Effects." The American Economic Review, 92(5): 1644-1655.

Horowitz, John K. And Kenneth E. McConnell. 2002. "A Review of WTA/WTP Studies.” The Journal of Environmental Economics and Management, 44: 426-447.

Kan, Kamhon. 2003. "Residential Mobility and Job Changes Under Uncertainty." Journal of Urban Economics, 54: 566-586.

Kaplow, Louis. 2005. "The Value of a Statistical Life and the Coefficient of Relative Risk Aversion." The Journal of Risk and Uncertainty, 31 (1): 23-34.

Kapteyn, Arie and Federica Teppa. 2002. "Subjective Measures or Risk Aversion and Portfolio Choice." RAND Corporation, Labor and Population Program Working Paper Series, DRU-2802, 02-03 (February).

Khwaja, Ahmed, Dan Silverman, and Frank Sloan. 2007. "Time Preference, Time Discounting and Smoking Decisions." Journal of Health Economics, 26: 927-949.

Kimball, Miles S., Claudia R. Sahm, and Matthew D. Shapiro. 2007. "Imputing Risk Tolerance from Survey Responses.” Manuscript, Department of Economics, The University of Michigan.

Kruse, Jamie Brown, and Mark A. Thompson. 2003. "Valuing Low Probability Risk: Survey and Experimental Evidence." Journal of Economic Behavior and Organization, 50: 495505.

Lahiri, Kajal, and Jae G. Song. 2000. "The Effect of Smoking on Health Using a Sequential Self-Selection Model." Health Economics, 9: 491-511.

List, John A. 2006. "Field Experiments: A Bridge between Lab and Naturally Occurring Data." Advances in Economic Analysis \& Policy, 6(2): 1-45.

Luoh, Ming-Ching, and Frank Stafford. 2007. "Estimating Risk Tolerance from the 1996 PSID.” Available on-line at: http://psidonline.isr.umich.edu/Data/Documentation /Cbks/ Support.html.

Lusardi, Annamaria. 1998. "On the Importance of the Precautionary Saving Motive." American Economic Review, 88 (2): 449-453. 
Lusk, Jayson L and Keith H. Coble. 2005. "Risk Perceptions, Risk Preference, and Acceptance of Risky Food." American Journal of Agricultural Economics, 87(2): 393-405.

Mokdad, Ali H., James S. Marks, Donna F. Stroup, and Julie L. Gerberding. 2004. “Actual Causes of Death in the United States, 2000." Journal of the American Medical Association; 291: 1238-1245.

National Highway Traffic Safety Administration (NHTSA). 2006. Seat Belt Use in 2006 Overall Results. DOT HS 810-677. U.S. Department of Transportation, November.

National Highway Traffic Safety Administration (NHTSA). 1997. Summary of State Speed Laws. DOT HS 808-510. U.S. Department of Transportation, January.

Peltzman, Sam. 1975. "The Effects of Automobile Safety Regulation.” Journal of Political Economy, 83: 667-725.

Picone, Gabriel, Frank Sloan and Donald Taylor, Jr. 2004. "Effects of Risk and Time Preference and Expected Longevity on Demand for Medical Tests." The Journal of Risk and Uncertainty, 28 (1): 39-53.

Schmidt, Lucie. 2007. "Risk Preferences and the Timing of Marriage and Childbearing." Manuscript, Department of Economics, Williams College.

Sloan, Frank A. and Edward C. Norton. 1997. "Adverse Selection, Bequests, Crowding Out, and Private Demand for Insurance: Evidence from the Market for Long Term Care Insurance." Journal of Risk and Uncertainty, 15(3): 210-219.

van Ours, Jan C. 2004. "A Pint a Day Raises a Man's Pay; But Smoking Blows that Gain Away." Journal of Health Economics, 23 (5): 863-886.

Viscusi, W. Kip, and Joni Hersch. 2001. "Cigarette Smokers as Job Risk Takers.” The Review of Economics and Statistics, 83 (2): 269-280.

Weber, Elke U., Ann-Renee Blais, and Nancy E. Betz. 2005. “A Domain-specific Risk-attitude Scale: Measuring Risk Perceptions and Risk Behaviors." Journal of Behavioral Decision Making, 15: 263-290. 
Table 1. Lottery Choice Experiment

\begin{tabular}{|c|c|c|c|}
\hline Decision & Option A & Option B & $E(A)-E(B)$ \\
\hline 1 & $\begin{array}{l}\text { Receive } \$ 6.00 \text { if die throw is } 1 \\
\text { Receive } \$ 4.80 \text { if die throw is } 2-10\end{array}$ & $\begin{array}{l}\text { Receive } \$ 11.55 \text { if die throw is } 1 \\
\text { Receive } \$ 0.30 \text { if die throw is } 2-10\end{array}$ & 3.50 \\
\hline 2 & $\begin{array}{l}\text { Receive } \$ 6.00 \text { if die throw is } 1-2 \\
\text { Receive } \$ 4.80 \text { if die throw is } 3-10\end{array}$ & $\begin{array}{l}\text { Receive } \$ 11.55 \text { if die throw is } 1-2 \\
\text { Receive } \$ 0.30 \text { if die throw is } 3-10\end{array}$ & 2.49 \\
\hline 3 & $\begin{array}{l}\text { Receive } \$ 6.00 \text { if die throw is } 1-3 \\
\text { Receive } \$ 4.80 \text { if die throw is } 4-10\end{array}$ & $\begin{array}{l}\text { Receive } \$ 11.55 \text { if die throw is } 1-3 \\
\text { Receive } \$ 0.30 \text { if die throw is } 4-10\end{array}$ & 1.49 \\
\hline 4 & $\begin{array}{l}\text { Receive } \$ 6.00 \text { if die throw is } 1-4 \\
\text { Receive } \$ 4.80 \text { if die throw is } 5-10\end{array}$ & $\begin{array}{l}\text { Receive } \$ 11.55 \text { if die throw is } 1-4 \\
\text { Receive } \$ 0.30 \text { if die throw is } 5-10\end{array}$ & 0.48 \\
\hline 5 & $\begin{array}{l}\text { Receive } \$ 6.00 \text { if die throw is } 1-5 \\
\text { Receive } \$ 4.80 \text { if die throw is } 6-10\end{array}$ & $\begin{array}{l}\text { Receive } \$ 11.55 \text { if die throw is } 1-5 \\
\text { Receive } \$ 0.30 \text { if die throw is } 6-10\end{array}$ & -0.53 \\
\hline 6 & $\begin{array}{l}\text { Receive } \$ 6.00 \text { if die throw is } 1-6 \\
\text { Receive } \$ 4.80 \text { if die throw is } 7-10\end{array}$ & $\begin{array}{l}\text { Receive } \$ 11.55 \text { if die throw is } 1-6 \\
\text { Receive } \$ 0.30 \text { if die throw is } 7-10\end{array}$ & -1.53 \\
\hline 7 & $\begin{array}{l}\text { Receive } \$ 6.00 \text { if die throw is } 1-7 \\
\text { Receive } \$ 4.80 \text { if die throw is } 8-10\end{array}$ & $\begin{array}{l}\text { Receive } \$ 11.55 \text { if die throw is } 1-7 \\
\text { Receive } \$ 0.30 \text { if die throw is } 8-10\end{array}$ & -2.54 \\
\hline 8 & $\begin{array}{l}\text { Receive } \$ 6.00 \text { if die throw is } 1-8 \\
\text { Receive } \$ 4.80 \text { if die throw is } 9-10\end{array}$ & $\begin{array}{l}\text { Receive } \$ 11.55 \text { if die throw is } 1-8 \\
\text { Receive } \$ 0.30 \text { if die throw is } 9-10\end{array}$ & -3.54 \\
\hline 9 & $\begin{array}{l}\text { Receive } \$ 6.00 \text { if die throw is } 1-9 \\
\text { Receive } \$ 4.80 \text { if die throw is } 10\end{array}$ & $\begin{array}{l}\text { Receive } \$ 11.55 \text { if die throw is } 1-9 \\
\text { Receive } \$ 0.30 \text { if die throw is } 10\end{array}$ & -4.55 \\
\hline 10 & Receive $\$ 6.00$ if die throw is $1-10$ & Receive $\$ 11.55$ if die throw is $1-10$ & -5.55 \\
\hline
\end{tabular}


Table 2. Lottery Choices and Risk Aversion

\begin{tabular}{ccc}
\hline \hline Number of Safe Choices & Proportion of Subjects & Range of Relative Risk Aversion \\
\hline $0-1$ & 0.02 & $\mathrm{r}<-0.95$ \\
2 & 0.03 & $-0.95<\mathrm{r}<-0.49$ \\
3 & 0.09 & $-0.49<\mathrm{r}<-0.15$ \\
4 & 0.23 & $-0.15<\mathrm{r}<0.15$ \\
5 & 0.26 & $0.15<\mathrm{r}<0.41$ \\
6 & 0.20 & $0.41<\mathrm{r}<0.68$ \\
7 & 0.10 & $0.68<\mathrm{r}<0.97$ \\
8 & 0.03 & $0.97<\mathrm{r}<1.37$ \\
$9-10$ & 0.03 & $1.37<\mathrm{r}$ \\
\hline
\end{tabular}


Table 3. Explanatory Variable Definitions, and Sample Means (n=978)

\begin{tabular}{|c|c|c|}
\hline Variable & Definition & Mean \\
\hline CRRA & Coefficient of relative risk aversion (see text for details) & 0.257 \\
\hline Female & Equals 1 if subject is female; 0 otherwise. & 0.517 \\
\hline Age & Age at session, in years, calculated as session year minus birth year. & 45.35 \\
\hline Nonwhite & $\begin{array}{l}\text { Equals } 1 \text { if subject is Black, Hispanic, Asian or another race; } \\
0 \text { if White. }\end{array}$ & 0.133 \\
\hline $\begin{array}{l}\text { Current full time } \\
\text { student }\end{array}$ & $\begin{array}{l}\text { Equals } 1 \text { if subject reports employment status as full-time student; } \\
0 \text { otherwise. }\end{array}$ & 0.242 \\
\hline Some college & $\begin{array}{l}\text { Equals } 1 \text { if highest level of education completed is some college, and } \\
\text { subject is not a full time student; } 0 \text { otherwise. }\end{array}$ & 0.147 \\
\hline College degree & $\begin{array}{l}\text { Equals } 1 \text { if highest level of education completed is college degree, and } \\
\text { subject is not a full time student; } 0 \text { otherwise. }\end{array}$ & 0.261 \\
\hline Graduate degree & $\begin{array}{l}\text { Equals } 1 \text { if highest level of education completed is college degree, and } \\
\text { subject is not a full time student; } 0 \text { otherwise. }\end{array}$ & 0.299 \\
\hline $\begin{array}{l}\text { Household } \\
\text { Income } \$ 20-40 \mathrm{~K}\end{array}$ & $\begin{array}{l}\text { Equals } 1 \text { if annual pre-tax household income is } \$ 20,000-\$ 40,000 \text {; } \\
0 \text { otherwise, including "no answer." }\end{array}$ & 0.106 \\
\hline $\begin{array}{l}\text { Household } \\
\text { Income } \$ 40-60 \mathrm{~K}\end{array}$ & $\begin{array}{l}\text { Equals } 1 \text { if annual pre-tax household income is } \$ 40,001-\$ 60,000 \text {; } \\
0 \text { otherwise, including "no answer." }\end{array}$ & 0.135 \\
\hline $\begin{array}{l}\text { Household } \\
\text { Income } \$ 60-100 \mathrm{~K}\end{array}$ & $\begin{array}{l}\text { Equals } 1 \text { if annual pre-tax household income is } \$ 60,001-\$ 100,000 \text {; } \\
0 \text { otherwise, including "no answer." }\end{array}$ & 0.277 \\
\hline $\begin{array}{l}\text { Household } \\
\text { Income }>\$ 100 \mathrm{~K}\end{array}$ & $\begin{array}{l}\text { Equals } 1 \text { if annual pre-tax household income is } \$ 101,001 \text { or more; } \\
0 \text { otherwise, including "no answer." }\end{array}$ & 0.307 \\
\hline $\begin{array}{l}\text { Household } \\
\text { Income missing }\end{array}$ & $\begin{array}{l}\text { Equals } 1 \text { if no income range was reported on household income } \\
\text { question; } 0 \text { otherwise. }\end{array}$ & 0.094 \\
\hline Household size & Number of persons in household, including the subject. & 2.65 \\
\hline Catholic & Equals 1 if religious affiliation is Catholic; 0 otherwise. & 0.203 \\
\hline Protestant & Equals 1 if religious affiliation is Protestant; 0 otherwise. & 0.420 \\
\hline Other religion & $\begin{array}{l}\text { Equals } 1 \text { if religious affiliation is Jewish, Muslim or other; } \\
0 \text { otherwise. }\end{array}$ & 0.172 \\
\hline $\begin{array}{l}\text { Short term time } \\
\text { horizon }\end{array}$ & $\begin{array}{l}\text { Equals } 1 \text { if most important time period in planning saving and } \\
\text { spending is "next few months" or "next year"; } 0 \text { otherwise. }\end{array}$ & 0.160 \\
\hline $\begin{array}{l}\text { Long term time } \\
\text { horizon }\end{array}$ & $\begin{array}{l}\text { Equals } 1 \text { if most important time period in planning saving and } \\
\text { spending is "longer than ten years"; } 0 \text { otherwise. }\end{array}$ & 0.269 \\
\hline
\end{tabular}




\section{Table 4. Health Behavior Variable Definitions, Sample Means, and Correlations}

\begin{tabular}{|c|c|c|c|c|c|c|c|}
\hline \multirow[b]{2}{*}{ Variable } & \multirow[b]{2}{*}{ Definition } & \multirow[b]{2}{*}{ Mean } & \multicolumn{5}{|c|}{ Pairwise Tetrachoric Coefficient of Correlation with } \\
\hline & & & $\begin{array}{l}\text { Cigarette } \\
\text { Smoking }\end{array}$ & $\begin{array}{l}\text { Heavy } \\
\text { Episodic } \\
\text { Drinking }\end{array}$ & $\begin{array}{c}\text { Overweight/ } \\
\text { Obese }\end{array}$ & $\begin{array}{c}\text { Seat } \\
\text { belt } \\
\text { non-use }\end{array}$ & $\begin{array}{l}\text { Driving } \\
\text { over the } \\
\text { speed limit }\end{array}$ \\
\hline $\begin{array}{l}\text { Cigarette } \\
\text { smoking }\end{array}$ & $\begin{array}{l}\text { Equals } 1 \text { if subject smokes cigarettes "every } \\
\text { day" or "some days"; } \\
0 \text { if subject "never" smokes. }\end{array}$ & $\begin{array}{c}0.081 \\
(\mathrm{n}=977)\end{array}$ & 1.00 & & & & \\
\hline $\begin{array}{l}\text { Heavy episodic } \\
\text { drinking }\end{array}$ & $\begin{array}{l}\text { Equals } 1 \text { if average drinks per day }>=4 \text { for } \\
\text { female subjects, }>=5 \text { for male subject; } \\
0 \text { otherwise. }\end{array}$ & $\begin{array}{c}0.070 \\
(n=946)\end{array}$ & $\begin{array}{l}0.511^{* * *} \\
(n=945)\end{array}$ & 1.00 & & & \\
\hline $\begin{array}{l}\text { Overweight/ } \\
\text { Obese }\end{array}$ & $\begin{array}{l}\text { Equals } 1 \text { if body mass index }>=25 \text {; } \\
0 \text { otherwise. }\end{array}$ & $\begin{array}{c}0.468 \\
(\mathrm{n}=885)\end{array}$ & $\begin{array}{l}-0.128 \\
(\mathrm{n}=884)\end{array}$ & $\begin{array}{l}-0.166^{*} \\
(\mathrm{n}=860)\end{array}$ & 1.00 & & \\
\hline Seat belt non-use & $\begin{array}{l}\text { Equals } 1 \text { if subject wears seat belt "never," } \\
\text { "some of the time" or "most of the time"; } \\
0 \text { if "always or almost always." }\end{array}$ & $\begin{array}{c}0.101 \\
(n=978)\end{array}$ & $\begin{array}{l}0.348^{* * *} \\
(n=977)\end{array}$ & $\begin{array}{c}0.151 \\
(n=946)\end{array}$ & $\begin{array}{c}-0.041 \\
(n=885)\end{array}$ & 1.00 & \\
\hline $\begin{array}{l}\text { Driving over } \\
\text { the speed limit }\end{array}$ & $\begin{array}{l}\text { Equals } 1 \text { if subject drives over the speed limit } \\
\text { "always or almost always"; } \\
0 \text { if "most" or "some of the time," or "never." }\end{array}$ & $\begin{array}{c}0.092 \\
(\mathrm{n}=971)\end{array}$ & $\begin{array}{c}0.068 \\
(n=970)\end{array}$ & $\begin{array}{l}0.427^{* * *} \\
(n=939)\end{array}$ & $\begin{array}{l}-0.078 \\
(n=879)\end{array}$ & $\begin{array}{c}0.132 \\
(\mathrm{n}=971)\end{array}$ & 1.00 \\
\hline
\end{tabular}

NOTES: Statistical significance indicated by ${ }^{*}$ for 0.10 and ${ }^{* * *}$ for 0.01 or better. 
Table 5. Models of Specific Health Behaviors

\begin{tabular}{|c|c|c|c|c|c|}
\hline \multirow[b]{2}{*}{ Explanatory Variable } & \multicolumn{5}{|c|}{ Dependent Variable } \\
\hline & Cigarette Smoking & $\begin{array}{l}\text { Heavy Episodic } \\
\text { Drinking }\end{array}$ & Overweight/Obese & Seat Belt Non-use & $\begin{array}{l}\text { Driving over the } \\
\text { Speed Limit }\end{array}$ \\
\hline CRRA & $\begin{array}{r}-0.030^{*} \\
(1.87)\end{array}$ & $\begin{array}{c}-0.0001^{*} \\
(1.80)\end{array}$ & $\begin{array}{c}-0.102^{* *} \\
(2.34)\end{array}$ & $\begin{array}{r}-0.036^{*} \\
(1.66)\end{array}$ & $\begin{array}{l}-0.026 \\
(1.34)\end{array}$ \\
\hline Female & $\begin{array}{l}-0.010 \\
(0.75)\end{array}$ & $\begin{array}{c}-0.0001^{*} \\
(1.93)\end{array}$ & $\begin{array}{c}-0.278^{* * *} \\
(7.60)\end{array}$ & $\begin{array}{c}-0.037^{* *} \\
(2.02)\end{array}$ & $\begin{array}{c}-0.051^{* * *} \\
(2.99)\end{array}$ \\
\hline Nonwhite & $\begin{array}{l}0.021 \\
(1.03)\end{array}$ & $\begin{array}{c}-0.0001^{* *} \\
(1.96)\end{array}$ & $\begin{array}{l}0.046 \\
(0.79)\end{array}$ & $\begin{array}{l}0.037 \\
(1.32)\end{array}$ & $\begin{array}{l}-0.003 \\
(0.13)\end{array}$ \\
\hline Age & $\begin{array}{c}-0.002^{* * *} \\
(3.41)\end{array}$ & $\begin{array}{c}-0.00003^{* * *} \\
(4.49)\end{array}$ & $\begin{array}{c}0.004^{* * *} \\
(2.60)\end{array}$ & $\begin{array}{c}0.0002 \\
(0.24)\end{array}$ & $\begin{array}{c}-0.002^{* * *} \\
(3.48)\end{array}$ \\
\hline Some college & $\begin{array}{r}-0.037^{*} \\
(1.78)\end{array}$ & $\begin{array}{c}0.844^{* * *} \\
(8.26)\end{array}$ & $\begin{array}{l}0.061 \\
(0.63)\end{array}$ & $\begin{array}{c}-0.036 \\
(1.01)\end{array}$ & $\begin{array}{l}0.080 \\
(1.00)\end{array}$ \\
\hline College degree & $\begin{array}{c}-0.048^{* *} \\
(2.22)\end{array}$ & $\begin{array}{c}0.094^{* * *} \\
(7.00)\end{array}$ & $\begin{array}{l}0.032 \\
(0.34)\end{array}$ & $\begin{array}{l}-0.028 \\
(0.76)\end{array}$ & $\begin{array}{l}0.104 \\
(1.34)\end{array}$ \\
\hline Graduate degree & $\begin{array}{c}-0.087^{* * *} \\
(3.80)\end{array}$ & & $\begin{array}{l}0.038 \\
(0.41)\end{array}$ & $\begin{array}{c}-0.056 \\
(1.54)\end{array}$ & $\begin{array}{l}0.128 \\
(1.63)\end{array}$ \\
\hline Current full time student & $\begin{array}{c}-0.071^{* * *} \\
(3.48)\end{array}$ & $\begin{array}{c}0.581^{* * *} \\
(8.07)\end{array}$ & $\begin{array}{c}-0.280^{* * *} \\
(2.90)\end{array}$ & $\begin{array}{l}0.003 \\
(0.07)\end{array}$ & $\begin{array}{l}0.084 \\
(1.10)\end{array}$ \\
\hline Household Income $\$ 20-40 \mathrm{~K}$ & $\begin{array}{l}-0.001 \\
(0.04)\end{array}$ & $\begin{array}{c}-0.0001 \\
(0.96)\end{array}$ & $\begin{array}{l}-0.060 \\
(0.70)\end{array}$ & $\begin{array}{l}0.039 \\
(0.97)\end{array}$ & $\begin{array}{l}-0.039 \\
(1.47)\end{array}$ \\
\hline Household Income $\$ 40-60 \mathrm{~K}$ & $\begin{array}{l}-0.017 \\
(0.71)\end{array}$ & $\begin{array}{c}-0.0001^{* *} \\
(2.08)\end{array}$ & $\begin{array}{l}0.056 \\
(0.64)\end{array}$ & $\begin{array}{c}-0.010 \\
(0.28)\end{array}$ & $\begin{array}{c}-0.054^{* *} \\
(2.03)\end{array}$ \\
\hline Household Income $\$ 60-100 \mathrm{~K}$ & $\begin{array}{c}-0.045^{* *} \\
(2.06)\end{array}$ & $\begin{array}{c}-0.0001 \\
(0.90)\end{array}$ & $\begin{array}{l}0.011 \\
(0.13)\end{array}$ & $\begin{array}{c}-0.062^{*} \\
(1.95)\end{array}$ & $\begin{array}{c}-0.063^{* *} \\
(2.31)\end{array}$ \\
\hline
\end{tabular}


Table 5. Models of Specific Health Behaviors (continued)

\begin{tabular}{|c|c|c|c|c|c|}
\hline \multirow[b]{2}{*}{ Explanatory Variable } & \multicolumn{5}{|c|}{ Dependent Variable } \\
\hline & Cigarette Smoking & $\begin{array}{l}\text { Heavy Episodic } \\
\text { Drinking }\end{array}$ & Overweight/Obese & Seat Belt Non-use & $\begin{array}{l}\text { Driving over the } \\
\text { Speed Limit }\end{array}$ \\
\hline Household Income $\$ 100 \mathrm{~K}+$ & $\begin{array}{c}-0.008 \\
(0.34)\end{array}$ & $\begin{array}{c}-0.0001 \\
(0.75)\end{array}$ & $\begin{array}{c}-0.083 \\
(0.99)\end{array}$ & $\begin{array}{c}-0.076^{* *} \\
(2.39)\end{array}$ & $\begin{array}{c}-0.059^{* *} \\
(2.16)\end{array}$ \\
\hline Household Income missing & $\begin{array}{c}-0.038^{*} \\
(1.69)\end{array}$ & $\begin{array}{c}-0.00003 \\
(0.47)\end{array}$ & $\begin{array}{c}-0.140 \\
(1.46)\end{array}$ & $\begin{array}{r}-0.047 \\
(1.42)\end{array}$ & $\begin{array}{c}-0.041 \\
(1.43)\end{array}$ \\
\hline Household size & $\begin{array}{l}0.002 \\
(0.40)\end{array}$ & $\begin{array}{c}0.00002 \\
(1.07)\end{array}$ & $\begin{array}{l}0.026 \\
(1.46)\end{array}$ & $\begin{array}{c}0.021^{* * *} \\
(2.63)\end{array}$ & $\begin{array}{c}-0.0006 \\
(0.09)\end{array}$ \\
\hline Catholic & $\begin{array}{c}-0.031^{*} \\
(1.87)\end{array}$ & $\begin{array}{c}0.00002 \\
(0.33)\end{array}$ & $\begin{array}{l}0.063 \\
(1.10)\end{array}$ & $\begin{array}{c}-0.005 \\
(0.19)\end{array}$ & $\begin{array}{l}0.008 \\
(0.32)\end{array}$ \\
\hline Protestant & $\begin{array}{c}-0.045^{* * *} \\
(2.64)\end{array}$ & $\begin{array}{c}-0.0001^{*} \\
(1.75)\end{array}$ & $\begin{array}{l}0.062 \\
(1.23)\end{array}$ & $\begin{array}{c}-0.005 \\
(0.19)\end{array}$ & $\begin{array}{l}-0.022 \\
(1.05)\end{array}$ \\
\hline Other religion & $\begin{array}{c}-0.014 \\
(0.82)\end{array}$ & $\begin{array}{c}-0.0001^{* *} \\
(2.12)\end{array}$ & $\begin{array}{c}0.074 \\
(1.23)\end{array}$ & $\begin{array}{c}-0.015 \\
(0.57)\end{array}$ & $\begin{array}{c}-0.030 \\
(1.30)\end{array}$ \\
\hline Short term time horizon & $\begin{array}{c}-0.016 \\
(0.96)\end{array}$ & $\begin{array}{c}-0.00004 \\
(0.85)\end{array}$ & $\begin{array}{c}0.011 \\
(0.20)\end{array}$ & $\begin{array}{c}0.041 \\
(1.61)\end{array}$ & $\begin{array}{c}0.0004 \\
(0.02)\end{array}$ \\
\hline Long term time horizon & $\begin{array}{l}0.003 \\
(0.16)\end{array}$ & $\begin{array}{c}0.0001 \\
(1.40)\end{array}$ & $\begin{array}{c}-0.026 \\
(0.61)\end{array}$ & $\begin{array}{c}-0.005 \\
(0.22)\end{array}$ & $\begin{array}{l}0.005 \\
(0.27)\end{array}$ \\
\hline Number of Observations & 977 & 946 & 885 & 978 & 971 \\
\hline Dependent Mean & 0.081 & 0.070 & 0.468 & 0.101 & 0.092 \\
\hline
\end{tabular}


Table 6. Alternate Model Specifications Using Summary Measures of Risk Behavior

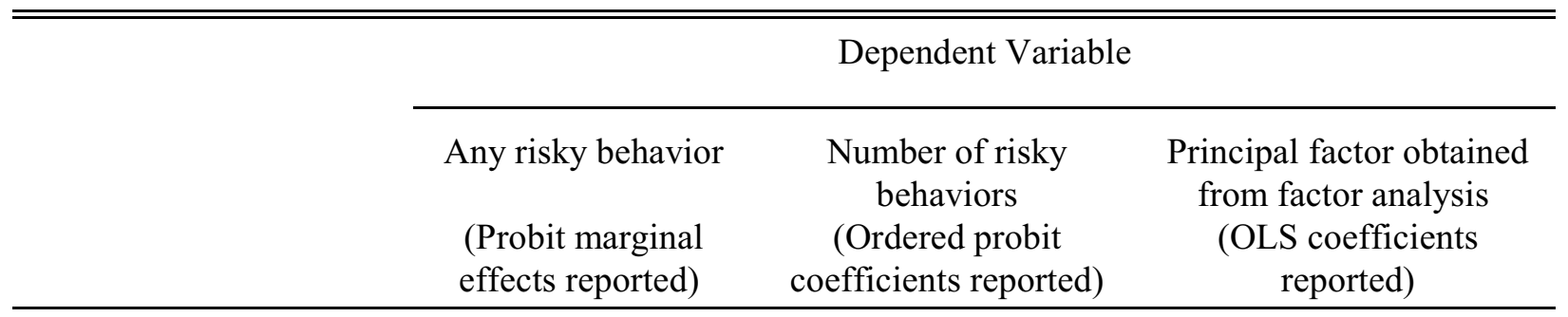

Panel A:

All 5 behaviors used to construct dependent variables

\begin{tabular}{lccc} 
CRRA & $-0.124^{* * *}$ & $-0.349^{* * *}$ & $-0.029^{* *}$ \\
& $(3.09)$ & $(3.70)$ & $(2.01)$ \\
Dependent Mean & 0.640 & 0.819 & 0.054 \\
Sample size & 889 & 853 & 853 \\
\hline
\end{tabular}

Panel B:

Overweight/obese indicator omitted in construction of dependent variables

$\begin{array}{lccc}\text { CRRA } & -0.078^{* *} & -0.296^{* * *} & -0.034^{* * *} \\ & (2.21) & (2.67) & (2.47) \\ \text { Dependent Mean } & 0.266 & 0.338 & 0.090 \\ \text { Sample size } & 952 & 938 & 938\end{array}$

Notes: All models also include all of the explanatory variables shown in Table 5. Statistical significance indicated by ${ }^{*}$ for $0.10,{ }^{* *}$ for 0.05 and ${ }^{* * *}$ for 0.01 or better. CRRA is the coefficient of relative risk aversions as defined in the text. 


\section{Appendix 1. Experiment Instructions}

\section{INSTRUCTIONS}

ID Number:

You will be making choices between two lotteries, such as those represented as "Option A" and "Option B" below. The money prizes are determined by throwing a ten-sided die. Each outcome, 1, $2,3,4,5,6,7,8,9,10$, is equally likely. Thus if you choose Option A, you will have a 1 in 10 chance of earning $\$ 6.00$ and a 9 in 10 chance of earning $\$ 4.80$. Similarly, Option B offers a 1 in 10 chance of earning $\$ 11.55$ and a 9 in 10 chance of earning $\$ 0.30$.

\begin{tabular}{|c|c|c|c|}
\hline Decision & Option A & Option B & $\begin{array}{l}\text { Your Choice } \\
\text { Circle One }\end{array}$ \\
\hline $1 \mathrm{st}$ & $\begin{array}{l}\$ 6.00 \text { if the die is } 1 \\
\$ 4.80 \text { if the die is } 2-10\end{array}$ & $\begin{array}{l}\$ 11.55 \text { if the die is } 1 \\
\$ 0.30 \text { if the die is } 2-10\end{array}$ & $\mathbf{A}$ or $\mathbf{B}$ \\
\hline
\end{tabular}

Each row of the decision table contains a pair of choices between Option A and Option B.

You make your choice by circling either "A" or "B" in the far right hand column of the table. Only one option in each row (i.e. for each Decision) can be circled.

Decision

$1 \mathrm{st}$

2nd
Option A

$\$ 6.00$ if the die is 1

$\$ 4.80$ if the die is $2-10$

$\$ 6.00$ if the die is $1-2$

$\$ 4.80$ if the die is $3-10$
Option B

$\$ 11.55$ if the die is 1 $\$ 0.30$ if the die is $2-10$

$\$ 11.55$ if the die is $1-2$

$\$ 0.30$ if the die is $3-10$
Your Choice

Circle One

A or B

A or $\mathbf{B}$

Even though you will make ten decisions, only one of these will end up being used. The selection of the one to be used depends on the throw of a ten-sided die. No decision is any more likely to be used than any other, and you will not know in advance which one will be selected, so please think about each one carefully. The first throw of the ten-sided die fixes the row (i.e. the Decision) that will be used to determine your earnings. For example, suppose that you make all ten decisions and the throw of the die is 9 , then your choice, A or B, for decision 9 below would be used and the other decisions would not be used.

$\begin{array}{cccc}\text { Decision } & \text { Option A } & \text { Option B } & \begin{array}{c}\text { Your Choice } \\ \text { Circle One }\end{array} \\ \text { - } & \$ 6.00 \text { if the die is } 1-9 & \$ 11.55 \text { if the die is } 1-9 & \text { A or B } \\ \text { 9th } & \$ 4.80 \text { if the die is } 10 & \$ 0.30 \text { if the die is } 10 & \end{array}$


After the random die throw fixes the Decision row that will be used, we need to make a second die throw to determine the earnings for the Option you chose for that row. In Decision 9 below, for example, a throw of $1,2,3,4,5,6,7,8$, or 9 will result in the higher payoff for the option you chose, and a throw of 10 will result in the lower payoff.

Decision

9th

10 th
Option A

$\$ 6.00$ if the die is $1-9$

$\$ 4.80$ if the die is 10

$\$ 6.00$ if the die is $1-10$
Option B

$\$ 11.55$ if the die is $1-9$

$\$ 0.30$ if the die is 10

$\$ 11.55$ if the die is $1-10$
Your Choice

A or B

A or $\mathbf{B}$

For decision 10, the random die throw will not be needed, since the choice is between amounts of money that are fixed: $\$ 6.00$ for Option A and $\$ 11.55$ for Option B.

Making Ten Decisions: At the end of these instructions you will see a table with 10 decisions in 10 separate rows, and you choose by circling one choice (A or B) in the far right hand column for each of the 10 rows. You may make these choices in any order.

The Relevant Decision: One of the rows (i.e. Decisions) is then selected at random, and the Option (A or B) that you chose in that row will be used to determine your earnings. Note: Please think about each decision carefully, since each row is equally likely to end up being the one that is used to determine payoffs.

Determining the Payoff: After one of the decisions has been randomly selected, we will throw the ten-sided die a second time. The number is equally likely to be $1,2,3, \ldots 10$. This number determines your earnings for the Option (A or B) that you previously selected for the decision being used.

\section{Instructions Summary}

To summarize, you will indicate an option, A or B, for each of the rows by circling one choice in the far right hand column.

Then the throw of a ten-sided die fixes which row of the table (i.e. which Decision) is relevant for your earnings.

In that row, your decision fixed the choice for that row, Option A or Option B, and a final throw of the ten-sided die will determine the money payoff for the decision you made. 


\section{DECISION SHEET}

\begin{tabular}{|c|c|c|c|}
\hline Decision & Option A & Option B & $\begin{array}{c}\text { Your Decision } \\
\text { Circle One }\end{array}$ \\
\hline 1 & $\begin{array}{l}\$ 6.00 \text { if the die is } 1 \\
\$ 4.80 \text { if the die is } 2-10\end{array}$ & $\begin{array}{l}\$ 11.55 \text { if the die is } 1 \\
\$ 0.30 \text { if the die is } 2-10\end{array}$ & A or \\
\hline 2 & $\begin{array}{l}\$ 6.00 \text { if the die is } 1-2 \\
\$ 4.80 \text { if the die is } 3-10\end{array}$ & $\begin{array}{l}\$ 11.55 \text { if the die is } 1-2 \\
\$ 0.30 \text { if the die is } 3-10\end{array}$ & A or \\
\hline 3 & $\begin{array}{l}\$ 6.00 \text { if the die is } 1-3 \\
\$ 4.80 \text { if the die is } 4-10\end{array}$ & $\begin{array}{l}\$ 11.55 \text { if the die is } 1-3 \\
\$ 0.30 \text { if the die is } 4-10\end{array}$ & A or \\
\hline 4 & $\begin{array}{l}\$ 6.00 \text { if the die is } 1-4 \\
\$ 4.80 \text { if the die is } 5-10\end{array}$ & $\begin{array}{l}\$ 11.55 \text { if the die is } 1-4 \\
\$ 0.30 \text { if the die is } 5-10\end{array}$ & A or \\
\hline 5 & $\begin{array}{l}\$ 6.00 \text { if the die is } 1-5 \\
\$ 4.80 \text { if the die is } 6-10\end{array}$ & $\begin{array}{l}\$ 11.55 \text { if the die is } 1-5 \\
\$ 0.30 \text { if the die is } 6-10\end{array}$ & $\mathbf{A}$ or \\
\hline 6 & $\begin{array}{l}\$ 6.00 \text { if the die is } 1-6 \\
\$ 4.80 \text { if the die is } 7-10\end{array}$ & $\begin{array}{l}\$ 11.55 \text { if the die is } 1-6 \\
\$ 0.30 \text { if the die is } 7-10\end{array}$ & A or \\
\hline 7 & $\begin{array}{l}\$ 6.00 \text { if the die is } 1-7 \\
\$ 4.80 \text { if the die is } 8-10\end{array}$ & $\begin{array}{l}\$ 11.55 \text { if the die is } 1-7 \\
\$ 0.30 \text { if the die is } 8-10\end{array}$ & A or \\
\hline 8 & $\begin{array}{l}\$ 6.00 \text { if the die is } 1-8 \\
\$ 4.80 \text { if the die is } 9-10\end{array}$ & $\begin{array}{l}\$ 11.55 \text { if the die is } 1-8 \\
\$ 0.30 \text { if the die is } 9-10\end{array}$ & A or \\
\hline 9 & $\begin{array}{l}\$ 6.00 \text { if the die is } 1-9 \\
\$ 4.80 \text { if the die is } 10\end{array}$ & $\begin{array}{c}\$ 11.55 \text { if the die is } 1-9 \\
\$ 0.30 \text { if the die is } 10\end{array}$ & $\mathbf{A}$ or $\mathbf{B}$ \\
\hline 10 & $\$ 6.00$ if the die is $1-10$ & $\$ 11.55$ if the die is $1-10$ & $\mathbf{A}$ or $\mathbf{B}$ \\
\hline
\end{tabular}

Result of first die throw (to determine Decision):

Result of second die throw (to determine payoff):

Payoff: 


\section{Appendix 2. Survey Questions on Health Related Behaviors}

How often do you wear a seatbelt when driving or riding in a car? Always, or almost always

Most of the time

Some of the time

Never, or almost never

If you drive a car, how often do you drive over the speed limit?

Always, or almost always

Most of the time

Some of the time

Never, or almost never

Not Applicable; I don't drive a car

Do you now smoke cigarettes every day, some days, or not at all?

Every day

Some days

Not at all

I prefer not to answer this question.

A drink of alcohol is 1 can or bottle of beer, 1 glass of wine, 1 can or bottle of wine cooler, 1 cocktail, or 1 shot of liquor. During the past week, how many days did you have at least one drink of any alcoholic beverage?

(insert number)

I prefer not to answer this question.

On the days when you drank, about how many drinks did you drink on average? Type no answer if you prefer not to answer this question.

(insert number)

I prefer not to answer this question.

About how much do you weigh in pounds?

(insert number)

I prefer not to answer this question.

For your height, please enter two numbers, feet in the first box and inches in the second box. For example, a 5 foot 7 inch tall person would put a 5 for the first height question and a 7 for the second.

About how tall are you IN FEET?

(insert number)

I prefer not to answer this question

About how tall are you IN INCHES?

(insert number)

I prefer not to answer this question 